\title{
Breast cancer survival by immunohistochemistry-determined subtype: A retrospective study
}

\author{
Aura Erazo Valle-Solís ${ }^{1}$, Arturo Pabel Miranda-Aguirre', Josué Mora-Pérez², \\ Juan Antonio Pineda-Juárez ${ }^{3}$, Luis Ernesto Gallardo-Valencia ${ }^{4}$, Liberio Santana ${ }^{4}$, \\ Guadalupe Cervantes-Sánchez ${ }^{5}$ and Eduardo Cárdenas-Cárdenas ${ }^{*}$ \\ ${ }^{1}$ Neoplastic and Proliferative Disorders Division; ${ }^{2}$ Teaching and Research Sub-directorate; ${ }^{3}$ Biomedical Research Division; ${ }^{4}$ General Management; \\ ${ }^{5}$ Department of Medical Oncology. Centro Médico Nacional 20 de Noviembre, Instituto de Seguridad y Servicios Sociales de los Trabajadores del \\ Estado, City of Mexico, Mexico
}

\begin{abstract}
Background: Breast cancer subtype classification according to hormone receptors (HR) and human epidermal growth factor receptor 2 (HER2) using immunohistochemistry is the standard practice for therapeutic decision making. Objective: To design future studies information on characteristics and survival of each subtype is essential. Method: We conducted a retrospective study to analyze clinical and pathologic features as well as survival data according to breast cancer immunohistochemistry subtype. Results: There were 211 women with a $R H(+) / H E R 2(-)$ breast cancer subtype, $53 \mathrm{HR}(+) / H E R 2(+), 16 \mathrm{HER} 2(+)$ and 23 HR(-)/HER2(-), with a median overall survival in months of 39 (20.5-62.7), 42 (25.5-65), 42 (13.7-67.7) and 26 (11-78), respectively, for a 3.7 hazard ratio of death (95\% Confidence Interval [Cl]: 1.3-10.3) for the triple negative group as compared to the $H R(+) / H E R 2(-)$ group $(p=0.01)$. Conclusions: HR positive subtypes by immunohistochemistry where most frequent and showed a greater overall survival compared to the triple negative subtype.
\end{abstract}

KEY WORDS: Breast cancer. Immunohistochemistry. Molecular subtype. Survival.

\section{Introduction}

Breast cancer is the second most common neoplasm in the world and the most frequent in women. According to the World Health Organization (WHO), for the year of 2018, a total of 2.1 million new cases were estimated, accounting for $11.6 \%$ of all neoplasms. In addition, the WHO also estimated for that year a total of 626,679 deaths due to this condition'. Furthermore, breast cancer is also considered the fifth cause of death from cancer in the world and a public health problem².

In Mexico, breast cancer has been considered a public health problem since 2006, when it surpassed cervical cancer as the leading cause of cancer-related death in the country ${ }^{3}$. Current incidence is not well known; however, official figures from the National Institute of Statistics and Geography (INEGI - Instituto Nacional de Estadística y Geopgrafía) reported that during 2012 there were 26.6 cases per 100 thousand women older than 20 years and, during 2013, 26.2 cases in the same age group, which accounted for $30.8 \%$ of tumors detected in women ${ }^{4}$. More concerning is the fact that the breast cancer mortality rate increased from 8.4 deaths per 100,000 population in 2005 to 10.1 deaths per 100,000 in $2015^{5}$.

Currently, thanks to the advances in the field of molecular biology, breast cancer has been classified into four molecular subtypes, which Perou et al. ${ }^{6}$ describe, based on their gene expression, as luminal $A$, luminal B, human epidermal growth factor receptor 2 (HER2) overexpression and basal. Clinical evolution of each breast cancer molecular subtype is different and sets the standard for treatment along with other clinicopathological characteristics. Thus, luminal tumors, which are characterized by the expression of hormone
Correspondence:

*Eduardo Cárdenas-Cárdenas

E-mail: carcaredo84@hotmail.com
Date of reception: 06-03-2019

Date of acceptance: 19-03-2019

DOI: 10.24875/GMM.M19000288
Gac Med Mex. 2019;155 (Suppl 1):S39-S43

Contents available at PubMed www.gacetamedicademexico.com 
receptors $(\mathrm{HR})$ and a less aggressive behavior, benefit from hormone therapy with or without chemotherapy. Those that overexpress HER2 have a more aggressive behavior and benefit from targeted therapies such as trastuzumab and pertuzumab in combination with chemotherapy. Finally, basal-like neoplasms are mainly treated with chemotherapy and have the worst prognosis due to their biological behavior and fewer therapeutic options in comparison with the previously mentioned subtypes ${ }^{7-9}$.

Access to these genomic signatures for the classification of breast cancer is limited and, therefore, therapeutic decision-making in clinical practice is based on an approach to these subtypes by immunohistochemistry $(\mathrm{IHC})$ analysis of estrogen, progesterone and HER2 receptor status, which yields the HR(+), HER2(-), HR(+) HER2(+), HR (-)/HER2 (+) and HR (-)/HER2 (-) subtypes, which are equivalent to the luminal, luminal B HER2(+), HER2-overexpressing and basal-like subtypes of the molecular classification ${ }^{10-12}$.

Knowing the behavior of these breast cancer subtypes in our population is essential in order to be able to design new lines of research in this group of patients and, for this reason, we undertook the following study, whose purpose was to perform a retrospective review of breast cancer subtypes clinicopathological characteristics by means of $\mathrm{IHC}$ and associated survival.

\section{Method}

A retrospective cohort study was conducted at the National Medical Center 20 de Noviembre, of the Institute of Social Security and Services of State Workers (ISSSTE - Instituto de Seguridad y Servicios Sociales de los Trabajadores del Estado), of Mexico City, Mexico. Patient data were obtained from information registries and patient records of the period encompassed from January 2004 to December 2015. Approval of the study and data registration were authorized by the hospital's research, ethics and biosafety committees.

Female patients older than 18 years with a histopathological diagnosis of breast cancer were included. Patients were identified according to the presence or not of estrogen, progesterone and HER2 receptors; subsequently they were sub-classified into the following subtypes by IHC: 1) HR(+)/HER2(-); 2) HR(+)/HER2(+); 3) HER2(+), and 4) HR(-)/HER2(-). In addition, demographic variables (age), clinical variables (disease stage, positive lymph nodes, tumor size) and type of treatment (surgery, chemotherapy, radiotherapy, hormone therapy) were analyzed.
Overall survival was defined as the time elapsed from breast cancer initial diagnosis to the death of the patient and disease or progression-free survival as the time elapsed from the start of treatment to the recurrence or progression of the disease.

Statistical analysis was performed with the SPSS ${ }^{\circledR}$ program, version 24 (SPSS Inc., Chicago, IL, USA). Continuous variables were presented as means and standard deviation, and categorical variables as absolute and relative frequencies. For the comparison of groups, an independent Student t-test was used, and for categorical variables, Pearson's chi-square test or Fisher's exact test. For survival analysis, the KaplanMeier test was used together with the log-rank test. In addition, a multivariate analysis was carried out using Cox proportional risks to estimate the hazard ratio with $95 \%$ confidence intervals for the variables of interest (overall survival and progression-free survival) adjusting the data for variables potentially predictive of mortality. A degree of significance $(p<0.05)$ was considered statistically significant.

\section{Results}

A total of 303 breast cancer cases were observed. Regarding the IHC subtype, $69.6 \%$ of patients were $\mathrm{HR}(+)$ and HER2(-), 17.5\% HR(+)/HER2(+), 7.6\% triple negative, HR(-)/HER2(-), and 5.3\% were HER2(+). Median age in the study groups ranged from 51 to 56 years $(p>0.30)$. Among the clinical variables, a larger proportion of locally advanced stages was observed (IIB, IIIA, IIIB and IIIC) in comparison with early stages (I and IIA) and metastatic disease (IV) in all study groups, without significant differences being found $(p=0.30)$. Regarding the type of treatment received, statistically significant differences $(p>0.001)$ were observed between study groups in hormone therapy, with a larger proportion in the $\mathrm{HR}(+) / \mathrm{HER} 2(-)$ group $(n=174)$ in comparison with the $\mathrm{HR}(+) / \mathrm{HER} 2(+)$ $(n=51)$, HER2 $(+)(n=4)$ and HR(-)/HER2(-) $(n=7)$ groups, as well as in surgical therapy $(p=0.01)$ in the HR(+)/HER2(-) group $(n=194)$ in comparison with the $\mathrm{RH}(+) / \mathrm{HER} 2(+)(\mathrm{n}=50), \mathrm{HER} 2(+)(\mathrm{n}=15)$ and HR(-)/ HER2(-) $(n=20)$ groups. The remaining variables did not show significant differences (Table 1).

Table 2 shows non-adjusted risks for overall survival in relation to age, clinical stage, type of treatment and subtypes by IHC; in the latter, a hazard ratio $(H R)=3$, (95\% Cl: $1.4-6.3 ; p<0.01)$ and $H R=2.3(95 \% \mathrm{Cl}$ : $1.07-5.2 ; p=0.03)$ were observed in the HR(-)/HER2(-) and HER2(+) groups, respectively. Subsequently, 
Table 1. Study population demographic, clinical and treatment characteristics

\begin{tabular}{|c|c|c|c|c|c|}
\hline Variable & $\begin{array}{c}\text { HR(+)/HER2(-) } \\
n=211(69.6 \%)\end{array}$ & $\begin{array}{c}\text { HR(+)/HER2(+) } \\
n=53(17.5 \%)\end{array}$ & $\begin{array}{c}\text { HER2(+) } \\
n=16(5.3 \%)\end{array}$ & $\begin{array}{l}\text { HR(-)/HER2(-) } \\
n=23(7.6 \%)\end{array}$ & $\mathbf{P}$ \\
\hline Age, years & $53(46-62)$ & $52(45.5-58.5)$ & $51.5(44.2-56)$ & $56(43-63)$ & 0.31 \\
\hline \multicolumn{6}{|l|}{ Clinical stage, n (\%) } \\
\hline I, IIA & $77(36.4)$ & $22(41.5)$ & $3(18.7)$ & $6(26.1)$ & \\
\hline$\|\mathrm{B},\| \mathrm{A},\|\mathrm{II},\| \mathrm{C}$ & $97(45.9)$ & $25(47.1)$ & $11(68.5)$ & $12(52.1)$ & 0.30 \\
\hline IV & $19(9)$ & $1(1.8)$ & $1(6.2)$ & $1(4.3)$ & \\
\hline Positive lymph nodes (number) & $1(0-5)$ & $1(0-4)$ & $5.5(3.7-9.2)$ & $1.5(0-4.25)$ & 0.06 \\
\hline Tumor size (mm) & $30(15-45)$ & $30(16.5-47.7)$ & $36.5(25-57.5)$ & $42.5(34-62.5)$ & 0.001 \\
\hline \multicolumn{6}{|l|}{ Type of treatment, n (\%) } \\
\hline Hormone therapy & $174(82.5)$ & $41(77.4)$ & $4(25)$ & $7(30.4)$ & $<0.001$ \\
\hline Surgery & $194(91.9)$ & $50(94.3)$ & $15(93.8)$ & $20(87)$ & 0.69 \\
\hline Chemotherapy & $181(85.5)$ & $47(88.7)$ & $15(93.8)$ & $23(100)$ & 0.01 \\
\hline Overall survival (months) & $39(20.5-62.7)$ & $42(25.5-65)$ & $42(13.7-67.7)$ & $26(11-78)$ & 0.28 \\
\hline
\end{tabular}

Continuous variables are presented as medians and percentiles (p25-p75) and categorical variables as frequencies and percentages ( $n$ and \%). $\mathrm{HR}(+)$ : positive hormone receptors; HR(-): negative hormone receptors; HER2: human epidermal growth factor receptor 2.

Table 2. Non-adjusted Cox proportional risks for overall survival and recurrence/progression-free survival in women with breast cancer

\begin{tabular}{|c|c|c|c|c|c|c|}
\hline \multirow[t]{2}{*}{ Variable } & \multicolumn{3}{|c|}{ Overall survival } & \multicolumn{3}{|c|}{ Recurrence/progression-free survival } \\
\hline & $\begin{array}{c}H R \\
n=303\end{array}$ & $95 \% \mathrm{Cl}$ & p & $\begin{array}{c}H R \\
n=270\end{array}$ & $95 \% \mathrm{Cl}$ & $\mathbf{P}$ \\
\hline $\begin{array}{c}\text { Subtypes by IHC } \\
\text { HR(+)/HER2(-) } \\
\text { HR(+)/HER2(+) } \\
\text { HER2(+) } \\
\text { HR(-)/HER2(-) } \\
\text { Age (years) }\end{array}$ & $\begin{array}{c}1 \\
0.79 \\
2.3 \\
3 \\
1.01\end{array}$ & $\begin{array}{c}--- \\
0.36-1.7 \\
1.07-5.2 \\
1.4-6.3 \\
0.98-1.03\end{array}$ & $\begin{array}{c}--- \\
0.56 \\
0.03 \\
<0.01 \\
0.32\end{array}$ & $\begin{array}{c}1 \\
1.1 \\
1.8 \\
2 \\
0.99\end{array}$ & $\begin{array}{c}--- \\
0.5-2 \\
0.8-4 \\
0.9-4.4 \\
0.96-1\end{array}$ & $\begin{array}{l}--- \\
0.94 \\
0.12 \\
0.06 \\
0.56\end{array}$ \\
\hline $\begin{array}{c}\text { Clinical stage (\%) } \\
\text { I, IIA } \\
\text { IIB, IIIA, IIIB, IIIC } \\
\text { IV }\end{array}$ & $\begin{array}{c}1 \\
6.5 \\
30\end{array}$ & $\begin{array}{c}--- \\
2.3-18.6 \\
10-89.7\end{array}$ & $\begin{aligned} & --- \\
< & 0.01 \\
< & 0.01\end{aligned}$ & $\begin{array}{c}1 \\
4.9 \\
19.3\end{array}$ & $\begin{array}{c}--- \\
2.2-11 \\
5.5-67.8\end{array}$ & $\begin{array}{l}\quad-- \\
<0.01 \\
<0.01\end{array}$ \\
\hline $\begin{array}{c}\text { Type of treatment } \\
\text { Hormone therapy } \\
\text { Surgery } \\
\text { Chemotherapy }\end{array}$ & $\begin{array}{c}0.40 \\
0.13 \\
1.2\end{array}$ & $\begin{array}{c}0.23-0.70 \\
0.07-0.14 \\
0.49-3.1\end{array}$ & $\begin{array}{c}<0.01 \\
<0.01 \\
0.64\end{array}$ & $\begin{array}{c}0.5 \\
0.13 \\
1.7\end{array}$ & $\begin{array}{c}0.3-0.9 \\
0.06-0.28 \\
0.5-5.5\end{array}$ & $\begin{array}{c}0.03 \\
<0.01 \\
0.36\end{array}$ \\
\hline
\end{tabular}

Variables are presented as non-adjusted hazard ratios $(H R)$ and $95 \%$ confidence intervals.

$\mathrm{HR}(+)$ : positive hormone receptors; HR(-): negative hormone receptors; HER2: human epidermal growth factor receptor 2; IHC: immunohistochemistry.

these risks were adjusted (Table 3) for age, clinical stage and type of treatment, where the hazard ratio of the HR(-)/HER2(-) group showed an increase (HR: 3.7; $95 \% \mathrm{Cl}: 1.3-10.3 ; \mathrm{p}=0.01)$. In addition, survival curves were plotted according to the IHC subtypes (log-rank < 0.01) (Fig. 1).

Table 2 shows the non-adjusted risks for recurrence/progression-free survival in relation to age, clinical stage, type of treatment and subtypes by IHC. In the latter, a $H R=2$ was observed $(95 \% \mathrm{Cl}$ : 0.9-4.4; $p=0.06)$ in the HR(-)/HER2(-) group. Subsequently, said risk was adjusted for age, clinical stage and type of treatment (Table 3).

\section{Discussion}

Our results show overall survival differences in patients with breast cancer by immunohistochemical subtype. We observed that patients with $\mathrm{HR}(+)$ breast cancer are more common, who present with significantly smaller tumor size and lower number of positive lymph nodes, which is a reflection of a less aggressive 
Table 3. Adjusted Cox proportional hazards for overall survival and recurrence/progression-free survival in women with breast cancer

\begin{tabular}{|c|c|c|c|c|c|c|}
\hline & \multicolumn{3}{|c|}{ Overall survival } & \multicolumn{3}{|c|}{ Recurrenc/progressio-free survival } \\
\hline & $\mathrm{HR} n=303$ & $95 \% \mathrm{Cl}$ & p & $\mathrm{HR} n=270$ & $95 \% \mathrm{Cl}$ & $p$ \\
\hline \multicolumn{7}{|l|}{ Crude } \\
\hline $\begin{array}{l}\text { Subtypes by IHC } \\
\text { HR (+) /HER2 (-) } \\
\text { HR (+) /HER2+) } \\
\text { HER2(+) } \\
\text { HR (-)/HER2 (-) }\end{array}$ & $\begin{array}{c}1 \\
0.79 \\
2.3 \\
3\end{array}$ & $\begin{array}{c}--- \\
0.36-1.7 \\
1.07-5.2 \\
1.4-6.3\end{array}$ & $\begin{array}{c}--- \\
0.56 \\
0.03 \\
<0.01\end{array}$ & $\begin{array}{c}1 \\
1.1 \\
1.8 \\
2\end{array}$ & $\begin{array}{c}--- \\
0.5-2 \\
0.8-4 \\
0.9-4.4\end{array}$ & $\begin{array}{l}--- \\
0.94 \\
0.12 \\
0.06\end{array}$ \\
\hline \multicolumn{7}{|l|}{ Adjusted } \\
\hline $\begin{array}{l}\text { Subtypes by IHC } \\
\text { HR (+) /HER2(-) } \\
\text { HR (+)/HER2 (+) } \\
\text { HER2(+) } \\
\text { HR (-) /HER2 (-) }\end{array}$ & $\begin{array}{c}1 \\
1.1 \\
1.5 \\
3.7\end{array}$ & $\begin{array}{c}--- \\
0.49-2.8 \\
0.53-4.3 \\
1.3-10.3\end{array}$ & $\begin{array}{l}--- \\
0.70 \\
0.42 \\
0.01\end{array}$ & $\begin{array}{c}1 \\
1.2 \\
1.3 \\
1.6\end{array}$ & $\begin{array}{c}--- \\
0.5-2.6 \\
0.4-3.4 \\
0.6-4.7\end{array}$ & $\begin{array}{l}--- \\
0.64 \\
0.59 \\
0.32\end{array}$ \\
\hline
\end{tabular}

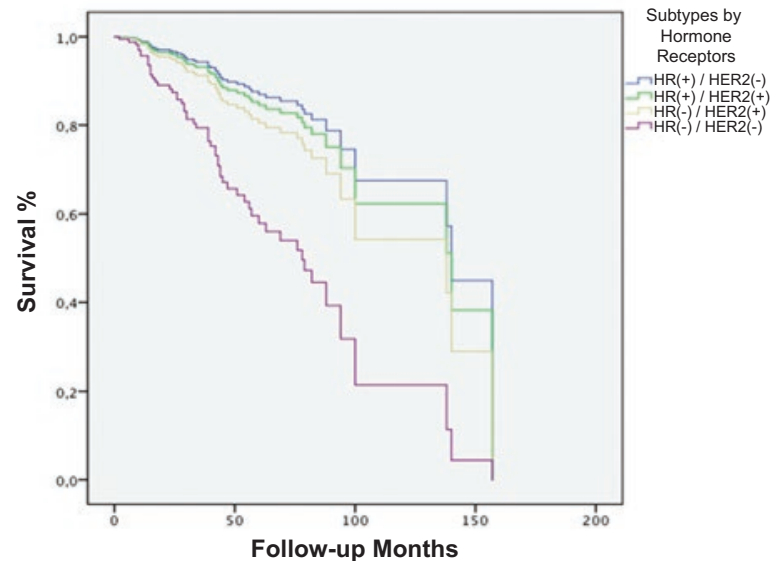

Figure 1. Overall survival Kaplan-Meier curves according to breast cancer subtypes by IHC.

$H R(+) / H E R 2(-)$

$H R(+) / H E R 2(+)$

$H R(-) / H E R 2(+)$

$H R(-) / H E R 2(-)$

Follow-up months

biological behavior and therefore of longer overall survival. In contrast, patients with breast cancer with a triple-negative subtype, which although less common, have larger tumors at diagnosis and a poorer prognosis, with shorter overall survival (adjusted HR: 3.7; 95\% Cl: 1.3-10.3).

In studies with European, Asian and United States populations, similar results to ours are observed, with a higher proportion of patients with $\mathrm{HR}(+)$ and better overall survival in this subgroup of patients. However, our proportion of HER2(+) patients, with or without positive HR, was higher, with $25 \%$ in comparison with
$17 \%$ or less reported by them ${ }^{13-18}$. Historically, patients with HER2(+) had a poor prognosis ${ }^{9}$, but with the advances in targeted therapies for this subtype of breast cancer, similar survival rates to those of the $\mathrm{HR}(+) /$ HER2(-) group have been reached ${ }^{19}$. In addition, there is a contrast in the percentage of patients with locally advanced disease, which in our study is larger than $50 \%$ of cases in comparison with less than $20 \%$ observed in developed countries ${ }^{13-15,17}$.

Regarding other studies in the Mexican population, the largest study reported is in a cohort of patients covered by Seguro Popular ${ }^{20}$, where out of 4,300 women, $60.7 \%$ were $\mathrm{HR}(+) / \mathrm{HER} 2(-)$ and had a better prognosis in comparison with women with triple-negative breast cancer with a $H R=2.16(95 \% \mathrm{Cl}: 1.69-2.75)$. The frequency of HER2(+)breast cancer is similar to ours, with $23 \%$ and, similarly, advanced stages of the disease are more common.

One study in a hospital of the Mexican Institute of Social Security (IMSS - Instituto Mexicano del Seguro Social) conducted by Pérez-Rodríguez ${ }^{21}$ reported a proportion of luminal $A$ breast cancer of $65 \%$ and $12 \%$ for luminal $B$, which is consistent with our results, with luminal subtypes with HR expression being the most common; however, the proportion of triple-negative disease of $14 \%$ was larger than that reported by us, which was $7.6 \%$. The differences in overall survival reported in this study were similar to those observed by us, which were larger in those patients who expressed HR in comparison with those not expressing HR. 
This is the first study to describe the characteristics and associated survival of breast cancer different subtypes determined by IHC in ISSSTE female beneficiaries, which adds important information together with studies on Seguro Popular and IMSS populations, which allows having a more complete picture of the reality of this disease in Mexico. Breast cancer is a curable disease if it is diagnosed at early stages, and it is therefore essential for the screening, diagnosis and referral programs of these patients to be improved, in order to reduce the frequency of cases detected at advanced stages of the disease, which continue to be most common in our population.

The main weakness of our study is that the sample is small and derived from a tertiary care referral hospital, and thus patient selection bias does not allow extrapolating the results to the situation of the entire institute. Breast cancer IHC subtypes allow molecular classification to be approached by means of the genomic signatures described by Perou et al. ${ }^{6}$. The use of IHC is considered a standard in the approach to breast cancer, as it provides way for addressing breast cancer molecular subtypes; however access to the genomic signatures necessary for molecular classification is limited, and the use of $\mathrm{IHC}$ in routine practice is therefore essential12,13.

In conclusion, the highest proportion of women with breast cancer in our population of beneficiaries have an $\mathrm{IHC}$ subtype with hormone receptor expression and this group of patients has better overall survival in comparison with triple-negative patients. The development of new therapeutic options for this poor prognosis group is essential, looking to achieve an impact such as that which has been achieved in HER2-positive patients.

\section{References}

1. Bray F, Ferlay J, Soerjomataram I, Siegel RL, Torre LA, Jemal A. Globa cancer statistics 2018: GLOBOCAN estimates of incidence and mortality worldwide for 36 cancers in 185 countries. CA Cancer J Clin. 2018;68:394-424.
2. Tao Z, Shi A, Lu C, Song T, Zhang Z, Zhao J. Breast cancer: Epidemiology and etiology. Cell Biochem Biophys. 2015;72:333-8.

3. Rodríguez Cuevas S, Capurso García M. Epidemiología del cáncer de mama. Ginecol Obstet Mex. 2006;74:585-93.

4. Estadísticas vitales. Defunciones generales y fetales [Internet]. México: INEGI 2016. Disponible en: http://www3.inegi.org.mx/rnm/index.php/ctalog/303

5. Aldaco-Sarvide F, Pérez-Pérez P, Cervantes-Sánchez G, Torrecillas-Torres L, Argentina Erazo-Valle-Solís A, Cabrera P, et al. Mortalidad por cáncer en México: actualización 2015. Gac Mex Oncol. 2008;17:28-34.

6. Perou CM, Sorlie T, Eisen MB, van de Rijn M, Jeffrey SS, Rees CA, et al. Molecular portraits of human breast tumours. Nature. 2000;406:747-52.

7. Wishart GC, Bajdik CD, Azzato EM, Dicks E, Greenberg DC, Rashbass J, et al. A population-based validation of the prognostic model PREDICT for early breast cancer. Eur J Surg Oncol. 2011;37:411-7.

8. Schmidt S, Monk JM, Robinson LE, Mourtzakis M. The integrative role of leptin, oestrogen and the insulin family in obesity-associated breast cancer: potential effects of exercise. Obes Rev. 2015;16:473-87.

9. Carey LA, Perou CM, Livasy CA, Dressler LG, Cowan D, Conway K, et al. Race, breast cancer subtypes, and survival in the Carolina Breast Cancer Study. JAMA. 2006;295:2492-502.

10. Bhargava R, Striebel J, Beriwal S, Flickinger JC, Onisko A, Ahrendt G, et al. Prevalence, morphologic features and proliferation indices of breast carcinoma molecular classes using immunohistochemical surrogate markers. Int J Clin Exp Pathol. 2009:2:444-55.

11. Rakha EA, El-Sayed ME, Reis-Filho JS, Ellis IO. Expression profiling technology: its contribution to our understanding of breast cancer. Histopathology. 2008;52:67-81.

12. Goldhirsch A, Winer EP, Coates AS, Gelber RD, Piccart-Gebhart M, Thurlimann $B$, et al. Personalizing the treatment of women with early breast cancer: highlights of the St Gallen International Expert Consensus on the Primary Therapy of Early Breast Cancer 2013. Ann Oncol. 2013;24:2206-23.

13. Park S, Koo JS, Kim MS, Park HS, Lee JS, Lee JS, et al. Characteristics and outcomes according to molecular subtypes of breast cancer as classified by a panel of four biomarkers using immunohistochemistry. Breast. 2012;21:50-7.

14. Engstrom MJ, Opdahl S, Hagen AI, Romundstad PR, Akslen LA, Haugen OA, et al. Molecular subtypes, histopathological grade and survival in a historic cohort of breast cancer patients. Breast Cancer Res Treat. 2013;140:463-73

15. Onitilo AA, Engel JM, Greenlee RT, Mukesh BN. Breast cancer subtypes based on ER/PR and Her2 expression: comparison of clinicopathologic features and survival. Clin Med Res. 2009;7:4-13.

16. Spitale A, Mazzola P, Soldini D, Mazzucchelli L, Bordoni A. Breast cancer classification according to immunohistochemical markers: clinicopathologic features and short-term survival analysis in a population-based study from the South of Switzerland. Ann Oncol. 2009;20;628-35.

17. Parise CA, Caggiano V. Breast cancer survival defined by the ER/PR/ HER2 subtypes and a surrogate classification according to tumor grade and immunohistochemical biomarkers. J Cancer Epidemiol. 2014;2014:11.

18. Blows FM, Driver KE, Schmidt MK, Broeks A, van Leeuwen FE, Wesseling $\mathrm{J}$, et al. Subtyping of breast cancer by immunohistochemistry to investigate a relationship between subtype and short and long term survival: a collaborative analysis of data for 10,159 cases from 12 studies. PLoS Med. 2010;7:e1000279.

19. Incorvati JA, Shah S, Mu Y, Lu J. Targeted therapy for HER2 positive breast cancer. J Hematol Oncol. 2013;6:38.

20. Reynoso-Noverón N, Villarreal-Garza C, Soto-Perez-de-Celis E, Arce-Salinas C, Matus-Santos J, Ramírez-Ugalde MT, et al. Clinical and epidemiological profile of breast cancer in Mexico: Results of the Seguro Popular. J Glob Oncol. 2017:3:757-64.

21. Pérez-Rodríguez G. [Prevalence of breast cancer sub-types by immunohistochemistry in patients in the Regional General Hospital 72, Instituto Mexicano del Seguro Social]. Cir Ciruj. 2015;83:193-8. 